\title{
Comparative Assessment of Manual, Rotary and Reciprocating Instruments for Removal of Root Fillings, Using Stereomicroscope: An in Vitro Study
}

\author{
Ali $\mathrm{A}^{1 *}$, Hussain $\mathrm{S}^{2}$, Metgud $\mathrm{S}^{1}$, Mishra $\mathrm{S}^{3}$, Sharma $\mathrm{A}^{4}$, Gupta $\mathrm{N}^{5}$ \\ ${ }^{I}$ Department of Conservative Dentistry and Endodontics, Pacific Dental College and Hospital, \\ Udaipur, Rajasthan, India; ${ }^{2}$ Department of Conservative Dentistry and Endodontics, Geetanjali \\ Dental College and Hospital, Udaipur, Rajasthan, India; ${ }^{3}$ Department of Conservative Dentistry \\ and Endodontics, Chattisgarh Dental College and Research, Rajnandgaon, Chattisgarh, India; \\ ${ }^{4}$ Department of Conservative Dentistry and Endodontics, $M$ M College of Dental Science and \\ Research, Ambala, Haryana, India; ${ }^{5}$ Private Practioner, New Delhi, India
}

\begin{abstract}
Background: Persistence of microorganism necessitates root canal retreatment. Retreatment requires complete removal of the root canal filling material, followed be further shaping, cleaning and reobturation. This in vitro study addressed the comparative evaluation of the efficacy of root canal filling material removal with different file systems.

Objective: To investigate the efficiency of Hedstrom (H; Dentsply Maillefer) file, protaper universal retreatment system (PTUR; Dentsply Maillefer), Mani NRT-GPR files (Mani, Japan) and WaveOne (WO; Dentsply Maillefer) reciprocating files in removing Gutta Percha (GP) and sealer from root canals.

Methods: Sixty canals with less than $10^{\circ}$ curvature from extracted human maxillary incisors were used. Root canal reinstrumentation was performed with H, PTUR, Mani NRT-GPR and WO files. Amount of residual root filling material (Gutta-percha and or sealer) were measured by using stereomicroscope. Data of GP or sealer remnants were statistically analyzed using one-way analysis of variance and Tukey test.
\end{abstract}

Results: There were no significant differences among 4 groups in terms of residual root filling material in the apical third $(p>0.05)$. H-file group showed highest amount of root residual root filling as compared to groups.

Conclusion: Reciprocating file system proved to be more efficient in removing the root canal fillings material than other retreatment file systems. $\mathrm{H}$ file group showed highest amount of root canal filling material.

Keywords: Gutta-Percha (GP), Mani NRT-GPR retreatment files, Nickel-Titanium (NiTi), Protaper universal retreatment files (PTUR)

\section{Introduction}

Effective debridement and three dimensional shaping of root canal system is the primary goal for successful results in endodontics. Mechanical instrumentation facilitates elimination of infected hard and soft tissues from root canal systems, creates access for the delivery of root canal irrigants and medicaments and subsequent placement of gutta percha with root canal sealer (root canal filling material). ${ }^{1,2}$

Endodontic failures may occurs even when the highest standard of protocols were followed. ${ }^{3}$ Endodontic failure may be attributed to improper

*Correspondence: Afzal Ali, Department of Conservative Dentistry and Endodontics, Pacific Dental College and Hospital, Udaipur, Rajasthan, India; e-mail: abu.ali.4k@gmail.com ORCID: https://orcid.org/0000-0002-0174-4656 cleaning and shaping of canal complexities, procedural errors or inability to establish hermatic seal, thereby facilitating survival or regrowth of bacteria in the root canal system. ${ }^{4}$

These bacteria and residual necrotic tissue can be the primary causative factor for periapical inflammation or pain. ${ }^{5,6}$ Technological advancement and patient awareness has led to increasing demand of preserving teeth, including teeth with endodontic failures. This requires the removal of the existing root fillings (gutta percha and or sealer), further instrumentation, disinfection, and refilling. ${ }^{7}$

Necrotic tissues, bacteria and biofilms are the key factors responsible for periapical inflammation. ${ }^{2}$ 
Surgical intervention may be employed, if nonsurgical management is not feasible to save the tooth. However, the option of orthograde retreatment is possible in almost all cases. ${ }^{7,8}$

Removal of gutta-percha (GP) is time consuming from well condensed root canals. Various instruments and techniques have been proposed to facilitate removal of root fillings (gutta-percha and or sealer). These includes endodontic hand instruments with or without gutta percha solvents, rotary instruments, heat carrying instruments and ultrasonic devices. Manual instrumentation for gutta-percha is tedious process. ${ }^{7}$

During instrumentation, apical extrusion is known to occur, which may, thereby induces inflammatory response. ${ }^{9}$ Root canal retreatment procedure aims at effective debridement thereby allowing access to and elimination of microorganisms and necrotic tissue remnants from the root canals. This in turn improves its prognosis. ${ }^{6}$

Traditionally to solubilize the gutta-percha, solvents were used. These includes chloroform, methylene chloride, eucalyptol, halothane, xylol, tetrahydrofuran and many more. ${ }^{10}$ However, the Japanese Ministry of Health and Welfare and U.S Food and Drug Administration has categorized chloroform with carcinogenic potential. ${ }^{11}$

NiTi files specifically designed for retreatment have been introduced. Rotary instrumentation is less time consuming than manual for root fillings removal. Nevertheless, substantial amount of root filling materials have been noticed on canal walls. The instruments specifically designed for retreatment includes Protaper Universal Retreatment File system (PTUR) (Dentsply Maillefer, Ballaigues, Switzerland), Mani NRTGPR (Mani, Japan) and WaveOne (Dentsply Maillefer, Ballaigues, Switzerland). ${ }^{6,12-14}$

The success rate of properly conducted root canal treatment can be as high as more than $90 \%$. However poor obturation quality may lead to failure of endodontic treatment. The morphologic aberrations and microbial factors may attribute to $8 \%$ failure rates for root canal treated teeth. ${ }^{15}$

Numerous studies have evaluated the root filling removal efficiency of various files system.
Tasmedir T, Er K, Yildirim T, Celik D reported that complete removal of root filling materials did not occur with any technique. In the previous studies, the protaper was shown to be more effective in root filling removal. However, schirrmeister, noticed similar residual root fillings. ${ }^{5}$

The previous studies in the literature reported that the manual files showed more residual root fillings as compared to rotary and reciprocating file systems. Hence based on the above findings the null hypothesis was considered and the study was designed to compare evaluate the efficiency of hand files and of rotary and reciprocating file systems, in removing root canal filling material.

\section{Material and Methods}

Specimen selection: This in vitro study was conducted at the department of Conservative Dentistry and Endodontics, pacific dental college and hospital, Udaipur, India, in a period of 8 months, during January-August 2017. Using the results of study conducted by Tasmedir et al, the sample size was calculted. ${ }^{5}$ Keeping a confidence interval of $95 \%$ and a power of at least $80 \%$, the sample size was calculated to be 15 per group, and were randomly divided into four groups.

Patients having non-carious periodontally compromised permanent maxillary incisors with single canal, closed root apex with a mean curvature less than $10^{\circ}$ at the apical third as per Schneider's method were collected from department of Oral and Maxillofacial Surgery in one month duration were included in the study. The patient had ASA PS score I and II. Patients having teeth with root fillings, resorption, calcification, fracture, caries or developmental anomalies were excluded from the study.

Initial root canal treatment: Following selection of teeth samples, decoronation was done to obtain a $18 \mathrm{~mm}$ standardized root length using a double diamond disc (KG Sorensen, Barueri, São Paulo, Brazil) operated at low speed and canal patency was established with no. $10 \mathrm{~K}$-file (Dentsply Maillefer, Ballaigues, Switzerland).

Coronal and middle third of radicular aspect was enlarged using Gates-Glidden drills (Dentsply Maillefer, Ballaigues, Switzerland) size 2 and 1. 
The canals were then prepared to size $30,0.6 \%$ taper using Neoendo Flex rotary file system (Neoendo Ltd. London, England). During the preparation, canals were irrigated with $3 \%$ sodium hypochlorite solution, $17 \%$ ethylene diamine tetraacetic acid (EDTA) and final flush with saline. With paper point (Kerr Corp., Romulus, MI) canals were dried and obturated with GP (Hygienic, Coltene/Whaledent Inc, Mahwah, NJ, USA), AH-Plus sealer (Dentsply De Trey, Konstanz, Germany) using warm vertical compaction technique with Fast-Pack (Eighteeth Medical Technology Co. Ltd, Jiangsu Province, China). This was followed by compaction with a cold plugger, to obtain the canal filling $2 \mathrm{~mm}$ short of canal orifice.

Samples were temporised with Cavit (3M-ESPE seefeld, Germany). Teeth were radiographed in bucco-lingual and mesio-distal views to confirm adequacy of root filling, following assessment of no voids, uniform radiopacity and canal filling till working length. Following this, final selection of the specimens was done and stored at 37 degree $\mathrm{C}$ in $100 \%$ humidity for one month.

Retreatment procedures: The temporary restorations were removed and teeth were randomly divided into 4 groups (15 in each group).

Group I: (Hedstrom Files) (Dentsply Maillefer, Ballaigues, Switzerland): The canals were reinstrumented with Hedstrom files from coronal to the apical portion with size 30,25 and 20 file, to remove root fillings until WL was achieved.

Group II: (Mani NRT-GPR Files) (Mani Inc., Japan): Mani NRT-GPR files were used to remove the obturation material from coronal to the apical portion of the root canals in a decreasing taper of 14 to 4 percent as specified by manufacturer. NiTi rotary files were used with a 2$3 \mathrm{~mm}$ amplitude push-pull movement and gentle apical pressure.

Group III: (ProTaper Universal Retreatment Files) (Dentsply Maillefer Ballaigues, Switzerland): The Protaper Universal Retreatment files were operated with X-Smart endomotor (Dentsply Maillefer Ballaigues, Switzerland) at $400 \mathrm{rpm}$ speed and $3 \mathrm{Ncm}$ torque. The obturation material was removed from coronal to the apical portion using D1, D2 and D3 files. Preparation of root canal was completed when the D3 instrument reached the working length (WL).

Group IV: (WaveOne Files): Size 40/0.08 taper WaveOne files (Dentsply Maillefer, Ballaigues, Switzerland) were used with a WaveOne motor (Dentsply Maillefer, Ballaigues, Switzerland) as per manufacturer's instructions.

Throughout the retreatment, the canals were irrigated with $5.25 \%$ sodium hypochlorite and $17 \%$ EDTA. Retreatment was deemed complete when no debris of GP/sealer was visible on the surface of instruments and canal walls were smooth.

Evaluation of Residual Root Canal Filling Material: With double-sided diamond disc, the teeth were grooved buccolingually and sectioned longitudinally with chisel. Both halves of the root canal were photographed (Olympus DP20, Olympus Tokyo, Japan) under stereomicroscope 8X magnification (Lawrence and Mayo, London). In JPEG format, the photographs were stored. The residual root fillings were measured in $\mathrm{mm}^{2}$ using image analyser software (Comef 4.3; OEG Messtechnik, Frankfurt, Germany) in the mesial and distal halves (figure 1). ${ }^{5}$

The area of the residual filling material and of canals were recorded and the percentage of remaining filling material on canal walls was calculated with the following equation: ${ }^{4}$

Area $\%$ of remaining filling material $=$ Area of remaining filling material $* 100$

Area of canal wall

To reduce inter-operator variability, a single operator carried out all endodontic procedure. To reduce the effect of evaluator fatigue as a variable, 5 photographs were viewed consecutively and then a 15 minute break was taken before the next evaluation session. In case of disagreement between the 2 evaluators a photograph was reevaluated jointly.

Statistical Analysis: The data were analyzed using Statistical Package for Social Science software (SPSS 15.0, IBM). The mean and standard deviation among the groups was calculated by one way ANOVA (one way analysis of variance) and 
multiple comparisons among the various groups was carried out by using Post Hoc Tukey Test with significance level of $<0.05 .(p<0.05)$

\section{Results}

Amongst all the groups, H-file group showed highest while WaveOne file group showed least amount of residual root filling material at both the coronal and middle thirds (table I).

Statistically significant differences were noted in the amount of residual root fillings at the coronal and middle thirds (both mesial and distal aspects), when H-file group was compared with WaveOne file group, Mani NRT-GPR file group with Wave One file group and ProTaper Universal Retreatment file group with WaveOne file group $(p<0.05)$ (table II).

Table I: Representing comparison between the study groups for residual root fillings.

\begin{tabular}{cccc}
\hline File Systems & Root Portion & Mean & S.D. \\
\hline \multirow{2}{*}{ H-File } & Coronal & 4106.10 & 899.27 \\
& Middle & 3147.40 & 725.68 \\
& Apical & 1138.45 & 876.17 \\
\hline \multirow{3}{*}{ Mani Nrt-Gpr File } & Coronal & 3169.90 & 1745.11 \\
& Middle & 2492.14 & 1619.31 \\
& Apical & 1043.00 & 659.02 \\
\hline \multirow{2}{*}{ Ptur File } & Coronal & 2717.62 & 1283.00 \\
& Middle & 2303.62 & 894.46 \\
& Apical & 1250.41 & 1192.14 \\
\hline \multirow{2}{*}{ Wave One File } & Coronal & 859.30 & 695.04 \\
& Middle & 991.12 & 437.40 \\
& Apical & 646.55 & 563.15 \\
\hline
\end{tabular}

No statistically significant differences were noted in the amount of residual root fillings at the coronal and middle third (both mesial and distal aspect) when $\mathrm{H}$ - file group was compared with Mani NRT-GPR file group, H-file file group with ProTaper Universal Retreatment file group and Mani NRT-GPR file group with ProTaper Universal Retreatment file group ( $p>0.05$ ) (table II).

Table II: Representing inter-group comparison among different groups by post hoc Tukey's test.

\begin{tabular}{|c|c|c|c|c|}
\hline $\begin{array}{c}\text { Root } \\
\text { Portion }\end{array}$ & $\begin{array}{c}\text { Comparison } \\
\text { Group }\end{array}$ & $\begin{array}{c}\text { Mean } \\
\text { Difference }\end{array}$ & $\begin{array}{c}p \\
\text { Value }\end{array}$ & Significance \\
\hline \multirow{6}{*}{ Coronal } & $\mathrm{H}-\mathrm{Nrt}$ & 936.20000 & .333 & NS \\
\hline & H- Ptur & 1388.48000 & .071 & NS \\
\hline & H- Wo & $3246.80000^{*}$ & .000 & S \\
\hline & Nrt-Ptur & 452.28000 & .841 & NS \\
\hline & Nrt-Wo & $2310.60000^{*}$ & .001 & $\mathrm{~S}$ \\
\hline & Ptur-Wo & $1858.32000^{*}$ & .009 & $\mathrm{~S}$ \\
\hline \multirow{6}{*}{ Middle } & $\mathrm{H}-\mathrm{Nrt}$ & 655.26000 & .483 & NS \\
\hline & H- Ptur & 843.78000 & .265 & NS \\
\hline & H- Wo & $2156.28000^{*}$ & .000 & $\mathrm{~S}$ \\
\hline & Nrt-Ptur & 188.52000 & .976 & NS \\
\hline & Nrt-Wo & $1501.02000^{*}$ & .011 & S \\
\hline & Ptur-Wo & $1312.50000^{*}$ & .032 & $\mathrm{~S}$ \\
\hline \multirow{6}{*}{ Apical } & H- Nrt & 95.45000 & .994 & NS \\
\hline & H- Ptur & -111.96000 & .991 & NS \\
\hline & H- Wo & 491.90000 & .579 & NS \\
\hline & Nrt-Ptur & -207.41000 & .948 & NS \\
\hline & Nrt-Wo & 396.45000 & .731 & NS \\
\hline & Ptur-Wo & 603.86000 & .405 & NS \\
\hline
\end{tabular}
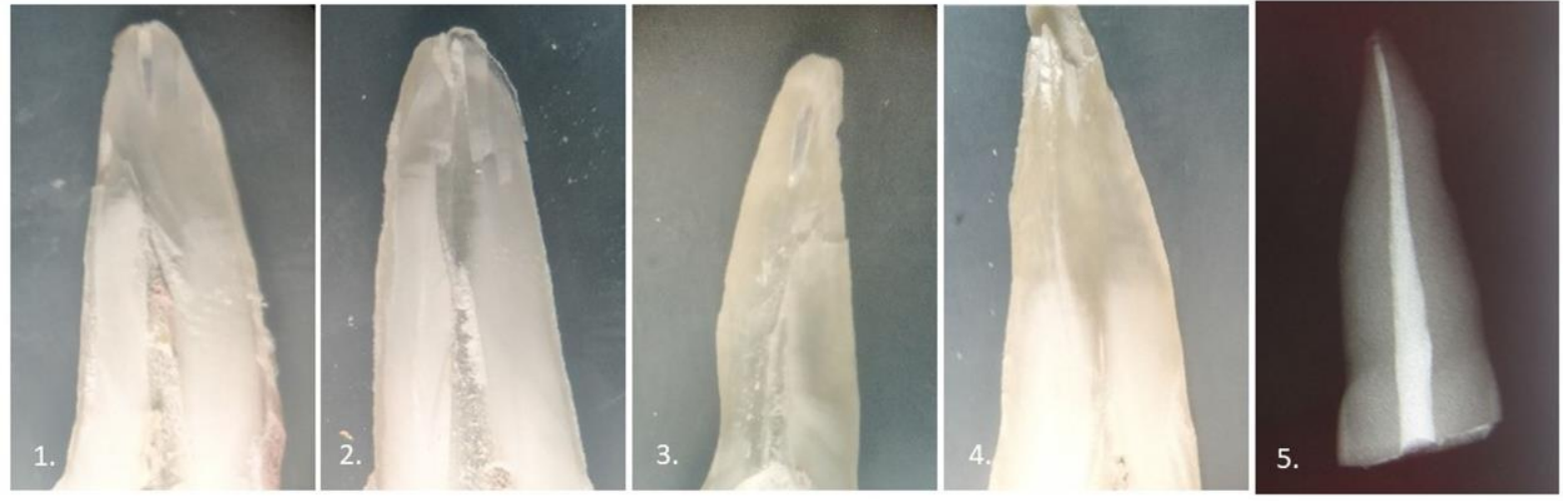

Figure 1: Representative Stereomicroscopic images at a magnification of $8 \mathrm{X}$ for each group (1: H File group, 2: Mani NRTGPR File group, 3: PTUR File group and 4: WaveOne Files group); 5: representative radiograph of a specimen

\section{Discussion}

Literature review has been shown that most of the endodontic failure requires non surgical or surgical retreatment or extraction. The endodontic retreatment success rate varies from 40 to $100 \%$.
The alterations in the natural course of the root canals caused by previous endodontic treatment does improves the success rate. ${ }^{16}$

The hand files, NiTi rotary files with or without GP solvents, gates-glidden drills, heat source, 
ultrasonic instruments and lasers have been used for root filling removal. The gutta-percha solvents serve as useful adjuncts to the mechanical action of instruments. ${ }^{4}$

Traditionally, H-Files have been used to remove the obturating material. Owing to its positive rake angle, $\mathrm{H}$-file facilitates gutta-percha removal in withdrawal strokes.

Better cleanliness of the canal walls have been seen upon using $\mathrm{H}$-files without solvent than with solvent. As the softened gutta-percha may get smeared over canal walls. ${ }^{10}$ Hence in the present study H-files were used without GP solvent.

The nickel-titanium (NiTi) alloys owing to its super elasticity and shape memory characteristics has revolutionized the field of endodontics. This unique property is attributed to its reversible phase transition from austenite to martensite and vice versa, thereby facilitating safer instrumentation especially in curved canals. ${ }^{17}$ The use of rotary NiTi instruments not only decreases operator and patient fatigue but also facilitate faster removal of root fillings during retreatment. ${ }^{18}$

The ProTaper rotary finishing files have been used for root filling removal, prior to PTUR. However, it yielded a fracture incidence of $22.7 \%$. PTUR is integrated with 3 retreatment files D1, D2, D3 for bulk removal of GP and two finishing files $(\mathrm{F} 4$, F5) for additional finishing of root canals. The active cutting tip of D1, absence of radial land and negative cutting angles permits more of cutting rather than cleaning action., ${ }^{2,5}$

Recently, the Mani NRT-GPR, has been developed comprising of four rotary files, two stainless steel files (S1, S2) and two NiTi files (N1, N2). The stainless-steel files were used for the preparation of coronal and middle third, while NiTi files were used for apical preparation. ${ }^{13}$

Another new concept has been introduced where endodontic files can be used for shaping the root canal as well as for retreatment purpose in reciprocating mode. One amongst such systems is WaveOne file system. The plastic color-coding over its handle deforms upon sterilization thereby preventing its reuse. ${ }^{12}$

Lateral compaction technique to obturate the root canals have been used in previous studies. This technique however influences the collection of cement within the gutta-percha. In the present study, warm vertical compaction with Fast Pack (Eighteeth Medical Technology Co. Ltd, Jiangsu Province, China) was used with the aim to enhance the volume of gutta-percha compared with the sealer. ${ }^{19}$

To evaluate the efficacy of root filling removal, various methods have been used including radiography, digitized images, clearing method, CBCT, sectioning and visualising them under stereomicroscope. The clearing procedures may influence the area of residual fillings within the root canals. Radiography provides 2-D representations of 3-D structures and image magnification. ${ }^{2,3}$

Computed Tomography (CT) has been used as it enables a three dimensional (3D) evaluation of the dental hard tissues. However, CBCT offers undistorted 3-D information of the maxillofacial structures with less radiation dosage. However the scanning is relatively costly and patient affordability is the main concern. ${ }^{20}$

Hence this study used vertical splitting of tooth and its assessment using stereomicroscope at $8 \mathrm{X}$ magnification. This method is easy to use and enables image standardization by keeping the distance between device and surface of the object constant. ${ }^{14,21}$

In the present study, stereomicroscopic images depicts the residual root fillings as area of residual root fillings (figure 1) in the canal, assessed using image analyser software (Comef 4.3; OEG Messtechnik, Frankfurt, Germany). ${ }^{5}$

Although time was not considered as a parameter in the present study, a significant finding was that PTUR, Mani NRT- GPR files and WO files required less time to remove root fillings than $\mathrm{H}$ file. Plasticization of gutta-percha during instrumentation facilitates rapid removal of root fillings. Also, the solvent softened gutta-percha may get forced into the intricacies of root canal system, thereby accentuating the challenges in retreatment. ${ }^{2,18}$ The residual root fillings seems to be penetrating more into canal irregularities and dentinal tubules following use of GP solvent. Additionally, it generate a thin film of GP on the root canal walls. Its removal is essential to umask 
bacteria or necrotic elements for thorough canal reinstrumentation and redisinfection. ${ }^{7}$ Hence, in the present study GP solvent was not preferred.

Several literatures have proposed techniques for removing the root canal fillings. Marfisi et al reported, none of the instrumentation techniques guarantees complete elimination of root canal fillings during retreatment. ${ }^{4} \mathrm{Gu}$ LS, Ling JQ, Wei $X$, Huang $X Y$, in their study, mentioned that regardless of single or combined action, it was impossible to remove all traces of root fillings from root canals with any of the retreatment techniques. The $10-17 \%$ of the canal area was covered by gutta-percha / sealer. ${ }^{6}$

Aydin B, Kose T, Caliskan MK in their study mentioned that all groups showed residual root filling on the canal walls. Overall $16-24 \%$ of the canal wall had residual root fillings. However, Dall'Agnol C, Hartmann MS, Barletta FB reported $62.21 \%$ of remaining filling material. ${ }^{2}$ In the present study, where H-files, WaveOne, ProTaper Universal Retreatment files and Mani NRT-GPR file were used for root filling removal, it was observed that irrespective of file system used, substantial amount of residual root filling was noted in all the groups. This is in accordance with the above mentioned studies.

Aydin B, Kose T, Caliskan MK reported irrespective of instrumentation technique, apical third showed more residual root filling than middle and coronal thirds. ${ }^{2}$ Gergi and Sabbagh, in their study reported less canal wall cleanliness in the apical third. ${ }^{[19]}$ In the present study also, all system left root filling material in the apical third.

Manual instrumentation proved inferior to protaper in terms of residual root fillings following retreatment in the study conducted by $\mathrm{Gu}$ et al, owing to its design features. ${ }^{6}$ By contrast, Schirrmeister et al while evaluating ProTaper and manual instrumentation in straight and curved root canals observed similar amounts of residual root canal filling material. ${ }^{16}$ This is agreement with the results of the present study, where in no statistically significant difference was found in the amount of residual root canal filling material in root canals when $\mathrm{H}$-file was compared with Mani NRT-GPR file and ProTaper Universal Retreatment file groups (table II).
Mani NRT-GPR files have a higher cutting ability due to positive rake angle of the lateral cutting edges. It cuts exceptionally well and resists fracture which eliminates the screwing in effect and reduces stress. ${ }^{13,22}$ Since Mani NRT-GPR rotary system is a new one, few scientific evidence are available in the literature and hence was used in the present study.

In the present study, though Mani NRT-GPR showed better root canal filling material removal than H-files $(p<0.05)$, the results were slightly inferior to ProTaper Universal retreatment files. There were no statistical significant difference observed, when Mani NRT-GPR was compared with H-files and PTUR ( $p>0.05$ ). However, WaveOne (WO) proved significantly better in removing root canal fillings as compared to Mani NRT-GPR files in the coronal and middle thirds (table II).

Reciprocating systems were not originally designed for use in retreatment procedures; nevertheless, they have been found to be efficacious in the removal of filling material from the root canals, owing to its brushing motion against the lateral walls of the canal. ${ }^{23}$ Also, the reciprocating motion reduces the cyclic and torsional fatigue to which the instrument is subjected. ${ }^{14}$

WaveOne has three radial lands in the apical 5 $\mathrm{mm}$, while the remaining $9 \mathrm{~mm}$ is similar to the ProTaper. It is used with reciprocating movement with unequal clockwise and counter clockwise rotation, thereby facilitating engagement of the filling material with the first motion and dislodgement of the root filling in the second motion. ${ }^{12,14}$

Mustafa et al in their study reported that all techniques left filling material inside the canal. Their results indicated that Wave One system group showed significantly less residual root filling material as compared to ProTaper and manual instruments. ${ }^{14}$

This study is in complete agreement with the above study, wherein WaveOne showed statistically superior results in the coronal and middle third of the root canals, when compared with ProTaper Universal Retreatment file system, H-file and Mani NRT-GPR file system. This can 
be attributed to the use of this system in reciprocating mode and lateral brushing action along the root canal walls, thereby plasticizing the filling material and facilitating its easier removal. However, in the apical third, all the file systems left behind similar amount of gutta-percha due to anatomical limitations.

As a methodological limitation, manual files, continuous rotation files and reciprocating file systems were compared in the present study. Another limitation was the splitting the teeth longitudinally and examining them under stereomicroscope which may even lead to loss of root filling material.

Hence, it would be of further interest to evaluate teeth with curved canals, different retreatment file systems, teeth obturated with different obturation techniques and sealers. Thus, the use of combination of retreatment files and shaping rotary files in conjunction with gutta-percha solvent are beneficial for faster, easier and effective nonsurgical retreatment.

\section{Conclusion}

The results encourage the use of reciprocating files in retreatment procedures. Owing to advances in technology, contemporary techniques for assessing the residual root canal filling material can also be employed.

\section{References}

1. Imura N, Kato AS, Hata GI, Uemura M, Toda T, Weine FA. comparison of the relative efficacies of four hand and rotary instrumentation techniques during endodontic retreatment. Int Endod J. 2000; 33:361-366.

2. Rodig T, Hausdorfer T, Konietschke F, Dullin C, Hahn W, Hulsmann M. Efficacy of D-RaCe and ProTaper Universal Retreatment NiTi instruments and hand files in removing gutta-percha from curved root canals - a micro-computed tomography study. Int Endod J. 2012; 45:580-9.

3. Fenoul G, Meless GD, Perez F. The efficacy of REndo rotary NiTi and stainless-steel hand instruments to remove gutta-percha and Resilon. Int Endod J. 2010; 43:135-41

4. Marfisi K, Mercade M, Plotino G, Duran-Sindreu F, Bueno R, Roig M. Efficacy of three different rotary files to remove gutta-percha and Resilon from root canals. Int Endod J. 2010; 43:1022-1028.
5. Tasdemir T, Er K, Yildirim T, Celik D. Efficacy of three rotary NiTi instruments in removing guttapercha from root canals. Int Endod J. 2008; 41:191196.

6. Gu LS, Ling JQ, Wei X, Huang XY. Efficacy of ProTaper Universal rotary retreatment system for gutta-percha removal from root canals. Int Endod J. 2008; 41:288-95.

7. Horvath SD, Altenburger MJ, Naumann M, Wolkewitz M, Schirrmeister JF. Cleanliness of dentinal tubules following gutta-percha removal with and without solvents: a scanning electron microscopic study. Int Endod J. 2009; 42:1032-8.

8. Betti L.V \& Bramante C.M. Quantec SC rotary instruments versus hand files for gutta-percha removal in root canal retreatment. Int Endod J. 2001; 34:514519.

9. Mollo et al. Efficacy of two Ni-Ti systems and hand files for removing gutta-percha from root canals. Int Endod J. 2012; 45:1-6.

10. Hülsmann M, Stotz S. Efficacy, cleaning ability and safety of different devices for gutta-percha removal in root canal retreatment. Int Endod J. 1997; 30:227233.

11. Manabu uemura, gin-ichiro hata, tadao toda, franklin s. effectiveness of Eucalyptol and d-limonene as gutta-percha solvents. J Endod. 1997; 23:739-741.

12. Yilmaz A, Kucukay S, Istektepe M, Sisli SN, Ersev $\mathrm{H}$, Karagoz-Kucukay I. Comparison of the shaping ability of waveone reciprocating files with or without glide path in simulated curved S-shaped root canals. J Int Soc Prevent Communit Dent. 2017; 7:S13-7.

13. Akhavan H, Bahrami Z, Moshari A, Sadighnia A, Haeri A, Ghannad S. The comparison of two rotary systems effect, ProTaper and NRTGPR, on the amount of debris extrusion during root canal retreatment. Ind J Fund App Life Sci. 2015; 5:141-6.

14. Kocak M M, Kocak S, Turker S A, Saglam BC. Cleaning efficacy of reciprocal and rotary systems in the removal of root canal filling material. J Conserv Dent. 2016; 19:184-8.

15. Da Silva et al. Effectiveness of Protaper, D-Race And Mtwo retreatment files with and without supplementary instruments in the removal of root canal filling material. Int Endod J. 2012; 45:927-932.

16. Schirrmeister JF, Wrbas KT, Meyer KM, Altenburger MJ, Hellwig E. Efficacy of different rotary instruments for gutta-percha removal in root canal retreatment. J Endod. 2006; 32:469-472.

17. Saberi N, Patel S, Mannocci F. Comparison of centring ability and transportation between four nickel titanium instrumentation techniques by micro- 
computed tomography. Int Endod J. 2017; 50:595603.

18. Kfir A, Tsesis I, Yakirevich, Matalon S, \& Abramovitz I. The efficacy of five techniques for removing root filling material: Microscopic versus Radiographic Evaluation. Int Endod J. 2012;45:35-41.

19. Gergi R, Sabbagh C. E ffectiveness of two nickeltitanium rotary instruments and a hand file for removing gutta-percha in severely curved root canals during retreatment:an ex vivo study. Int Endod J. 2007; 40:532-537.

20. Fernando Branco Barletta, Magda de Sousa Reis, Márcia Wagner, Janusa Casali Borges, Cristina Dall'Agnol. Computed tomography assessment of three techniques for removal of filling material. Aust Endod J. 2008; 34:101-105.

21. Rajender singh, ashu gupta, vishal sharma. Efficacy of two NiTi retreatment systems and hand files in removing gutta-percha and sealer from root canals filled with three different types of sealers. Dent J Adv studies. 2015; 3:71-79.

22. Gustavo Alberto Rubino, George Táccio de Miranda Candeiro, Laila Gonzales Freire, Elaine Faga Iglecias, Érico de Mello Lemos, Celso Luiz Caldeira, Giulio Gavini. Micro-CT Evaluation of Gutta-Percha Removal by Two Retreatment Systems, Iran Endod J 2018;13: 221-227.

23. Marcos de Azev^edo Rios, Alexandre Mascarenhas Villela, Rodrigo Sanches Cunha, Rafael Cortez Velasco, Alexandre Sigrist De Martin, Augusto Shoji Kato, Carlos Eduardo da Silveira Bueno. Efficacy of 2 Reciprocating Systems Compared with a Rotary Retreatment System for Gutta-percha Removal J Endod. 2014; 40:543-546. 